\title{
The role of FADD in pancreatic cancer cell proliferation and drug resistance
}

\author{
RONG ZHANG ${ }^{1}$, YINGTING LIU ${ }^{1}$, KAHINA HAMMACHE ${ }^{1}$,

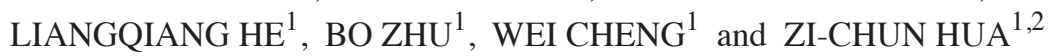 \\ ${ }^{1}$ State Key Laboratory of Pharmaceutical Biotechnology, College of Life Sciences and School of Stomatology, \\ Affiliated Stomatological Hospital, Nanjing University, Nanjing, Jiangsu 210093; \\ ${ }^{2}$ Changzhou High-Tech Research Institute of Nanjing University and Jiangsu Target Pharma Laboratories Inc., \\ Changzhou, Jiangsu 213164, P.R. China
}

Received July 13, 2015; Accepted September 6, 2016

DOI: $10.3892 / \mathrm{ol} .2017 .5636$

\begin{abstract}
Pancreatic cancer has one of the poorest patient outcomes and is highly resistant to chemotherapy. Identifying the molecular mechanisms involved in drug resistance is critical in the development of novel strategies to treat pancreatic cancer. The results of the present study demonstrate that Fas-associated death domain protein (FADD), a classical adaptor protein mediating apoptotic stimuli-induced cell death, protects pancreatic cancer cells from drug-induced apoptosis. In contrast to its classical apoptotic roles, it was observed that FADD is required for pancreatic cancer cell proliferation and that it is overexpressed to varying degrees in various types of pancreatic cancer cell. This leads to differing levels of drug resistance in pancreatic cancer cells, where drug resistance is positively correlated with FADD expression. Notably, the results of the present study demonstrate that FADD protects pancreatic cancer cells from drug-induced apoptosis, while RNA interference of FADD sensitizes drug-resistant cells to Adriamycin ${ }^{\circledR}$-mediated apoptosis. The results of the present study reveal unexpected roles for FADD in pancreatic cancer cell proliferation and drug resistance.
\end{abstract}

\section{Introduction}

Fas-associated death domain protein (FADD) is a classical adaptor protein involved in the cytoplasmic transduction of extracellular apoptotic signals by mediating the association

Correspondence to: Professor Zi-Chun Hua or Dr Wei Cheng, State Key Laboratory of Pharmaceutical Biotechnology, College of Life Sciences and School of Stomatology, Affiliated Stomatological Hospital, Nanjing University, 22 Hankou Road, Nanjing, Jiangsu 210093, P.R. China

E-mail: zchua@nju.edu.cn

E-mail: chengwe@outlook.com

Key words: Fas-associated death domain protein, pancreatic cancer, Adriamycin $^{\circledR}$, apoptosis, cell cycle of Fas and caspase-8 (1,2). FADD deficiency largely leads to compromised death receptor-mediated apoptosis $(3,4)$. However, previous studies have indicated that FADD is also required for embryonic development and lymphocyte differentiation, which is independent of apoptosis, suggesting that FADD interacts with non-apoptotic cooperators in vivo (5-7). Previously, the role of FADD in programmed necrosis has been revealed (8-10). Inhibition of programmed necrosis by inactivation of the receptor interacting protein 1 rescues FADD-deficient embryos from death (8).

As a pro-apoptotic protein, FADD functions as a tumor suppressor in certain types of cancer, including thymic lymphoblastic lymphoma and thyroid adenoma/adenocarcinoma (11). Downregulation of FADD has also been observed in the leukemic cells of acute myeloid leukemia patients (12). By contrast, FADD is overexpressed in certain types of cancer. FADD is located on chromosome 11q13, a region that is frequently amplified in several types of cancer, including lung, head and neck squamous cell carcinoma, laryngeal and pharyngeal carcinomas, and breast and ovarian carcinomas (13). FADD mRNA and protein levels are known to be increased in these forms of cancer (14-18). However, the role of FADD in these diseases remains to be fully elucidated.

Pancreatic cancer is one of the most lethal types of cancer worldwide and the early stages are difficult to diagnose, thus hindering prompt surgery, chemotherapy and radiotherapy (19). Additionally, pancreatic cancer is highly resistant to traditional chemotherapy and radiotherapy, which is primarily due to failure of inducing cell cycle arrest and apoptosis in pancreatic cancer cells (20). Cyclin-dependent kinase inhibitor 1 (p21) is a potent cell cycle inhibitor at G1 and $\mathrm{S}$ phase, and is usually suppressed in cancer cells (21). Therefore, identifying the mechanisms for $\mathrm{p} 21$ repression in pancreatic cancer cell in response to drugs may shed light on more efficient chemotherapy strategies.

Although the role of FADD in several types of cancer has been revealed, its role in pancreatic cancer remains to be elucidated. In the present study, it was demonstrated that FADD is overexpressed in pancreatic cancer cells. Furthermore, its expression level is correlated with pancreatic cancer cell drug resistance. FADD RNA interference resulted in increased cell 
cycle arrest and apoptosis in response to Adriamycin ${ }^{\circledR}$ treatment in drug-resistant cells. The present data indicates that FADD may have an important role in the development of drug resistance in pancreatic cancer cells.

\section{Materials and methods}

Cell culture. Pancreatic cancer cells (Colo357, Capan-1 and MIA-PaCa-2) were purchased from American Type Culture Collection (Manassas, VA, USA) and cultured in Dulbecco's modified Eagle's medium (DMEM) or RPMI-1640 (Invitrogen; Thermo Fisher Scientific, Inc., Waltham, MA, USA) with $10 \%$ fetal bovine serum (FBS; Invitrogen; Thermo Fisher Scientific, Inc.). Normal epithelial cell line (HPDE6) was a gift from Dr. Zhangjun Cheng (Southeast University, Nanjing, China) and cultured in RPMI-1640 with 10\% fetal bovine serum. All cells were maintained at $37^{\circ} \mathrm{C}$ with $5 \% \mathrm{CO}_{2}$ and a humidity of $95 \%$.

Cell viability assay. Colo357, Capan-1 and MIA-PaCa-2 cells $(2,000$ cells/well) were plated into each well of multiple 96-well plates and cultured for $24 \mathrm{~h}$ at $37^{\circ} \mathrm{C}$ in DMEM or RPMI-1640. Cells were then treated with 0, 0.25, 0.5, 1, 2 or $4 \mu \mathrm{M}$ of Adriamycin (Sigma-Aldrich; Merck Millipore, Darmstadt, Germany). Cell viability was determined by the 3-(4,5-dimethylthiazol-2-yl)-2,5-diphenyl tetrazolium (MTT) assay. Cells were incubated with MTT for $2 \mathrm{~h}$ at $37^{\circ} \mathrm{C}$. Following removal of the media containing MTT solution, the remaining dark blue formazan crystals in each well were dissolved in dimethyl sulfoxide. The absorbance was determined with a microplate reader. Each experiment was performed in triplicate.

RNA interference. FADD small interfering (siRNA) and negative control siRNA (NC siRNA) were synthesized by GenePharma Co., Ltd. (Shanghai, China). The FADD siRNA sequences used were as follows: sense, 5'-CACAGAGAA GGAGAACGCA-3'; and antisense, 5'-UGCGUUCUCCUU CUCUGUG-3' as described by Varfolomeev et al (22). The NC siRNA sequences used were as follows: sense, 5'-GGC AGCAACCGAGAAGAAA-3' and antisense, 5'-UUUCUU CUCGGUUGCUGCC-3', generated by siRNA Wizard v3.1 (InvivoGen, San Diego, CA, USA). The NC siRNA was a scrambled sequence of the FADD siRNA, which had no match in the human genome sequence. Colo-357 and Capan-1 cells $\left(5 \times 10^{5}\right)$ were plated in a 6 -well plate and cultured overnight at $37^{\circ} \mathrm{C}$ in RPMI-1640. siRNA and Lipofectamine ${ }^{\circledR} 2000$ Reagent (Invitrogen; Thermo Fisher Scientific, Inc.) were mixed and incubated with the cells in serum-free Gibco $^{\text {TM }}$ Opti-MEM (Thermo Fisher Scientific, Inc.) for $6 \mathrm{~h}$ at $37^{\circ} \mathrm{C}$. Fresh RPMI-1640 with $10 \%$ FBS was then added into the cells. For the effect of FADD on the proliferation of Colo-357, the concentrations of FADD siRNA were 0,10 , $25,50,100$ and $200 \mathrm{nM}$, and the concentrations of the total siRNA were made up to $200 \mathrm{nM}$ with NC siRNA for those transfections with a FADD siRNA concentration $<200 \mathrm{nM}$. For the effect of FADD on the drug resistance of Colo-357 and Capan-1, the concentration of FADD siRNA was $100 \mathrm{nM}$ and cells were treated with Adriamycin following $48 \mathrm{~h}$ of siRNA transfection.

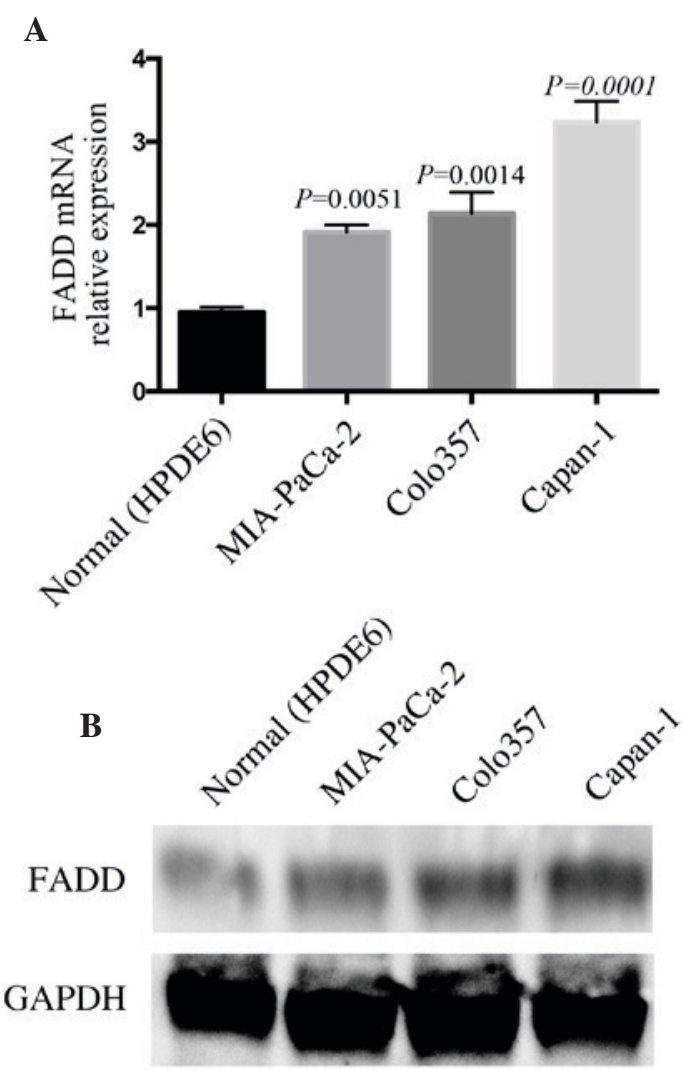

Figure 1. FADD is overexpressed in pancreatic cancer cells. (A) Normalized mRNA levels of FADD among pancreatic cells $(n=3)$. Values are presented as the mean \pm standard deviation. (B) Western blot analysis of FADD and GAPDH protein levels in pancreatic cancer cells. FADD, Fas-associated death domain protein; GAPDH, glyceraldehyde 3-phosphate dehydrogenase.

Western blotting. Briefly, cells were collected and washed with phosphate-buffered saline (PBS) and lysed in lysis buffer (20 mM Tris- $\mathrm{HCl}$ ( $\mathrm{pH} 7.5), 150 \mathrm{mM} \mathrm{NaCl}, 1 \mathrm{mM} \mathrm{Na}_{2}$ EDTA, 1 mM EGTA, $1 \%$ Triton, $2.5 \mathrm{mM}$ sodium pyrophosphate, $1 \mathrm{mM}$ beta-glycerophosphate, $1 \mathrm{mM} \mathrm{Na}_{3} \mathrm{VO}_{4}, 1 \mu \mathrm{g} / \mathrm{ml}$ leupeptin) for $30 \mathrm{~min}$ on ice, and subsequently centrifuged at $11,700 \mathrm{x} g$ for $10 \mathrm{~min}$ at $4^{\circ} \mathrm{C}$. The supernatants were collected. Western blotting was performed, as described by Cheng et al (23). Briefly, $50 \mu \mathrm{g}$ of protein from each sample were separated by using SDS-PAGE on a $12 \%$ SDS gel and subsequently transferred onto PVDF membranes (Merck Millipore). The membranes were then blocked in 5\% non-fat milk in Tris-buffered saline containing $0.1 \%$ Tween 20 for $1 \mathrm{~h}$ at room temperature and probed with primary antibodies at a dilution of 1:500 overnight at $4^{\circ} \mathrm{C}$ (anti-FADD; cat. no. sc-5559; anti-p21; cat. no. sc-6246; anti-GAPDH; cat no. sc-47724), then probed with corresponding horseradish peroxidase-conjugated secondary antibodies at a dilution of 1:5,000 (goat anti-mouse IgG-HRP; cat. no. sc-2302; goat anti-rabbit IgG-HRP; cat no. sc-2301) (all Santa Cruz Biotechnology, Inc., Dallas, TX, USA). Bands were visualized with 20X LumiGLO ${ }^{\circledR}$ Reagent and 20X Peroxide (cat. no. 7003; Cell Signaling Technology, Inc., Danvers, MA, USA).

Cell cycle analysis. Following siRNA transfection and Adriamycin treatment, Capan-1 cells were subjected to cell cycle 
A
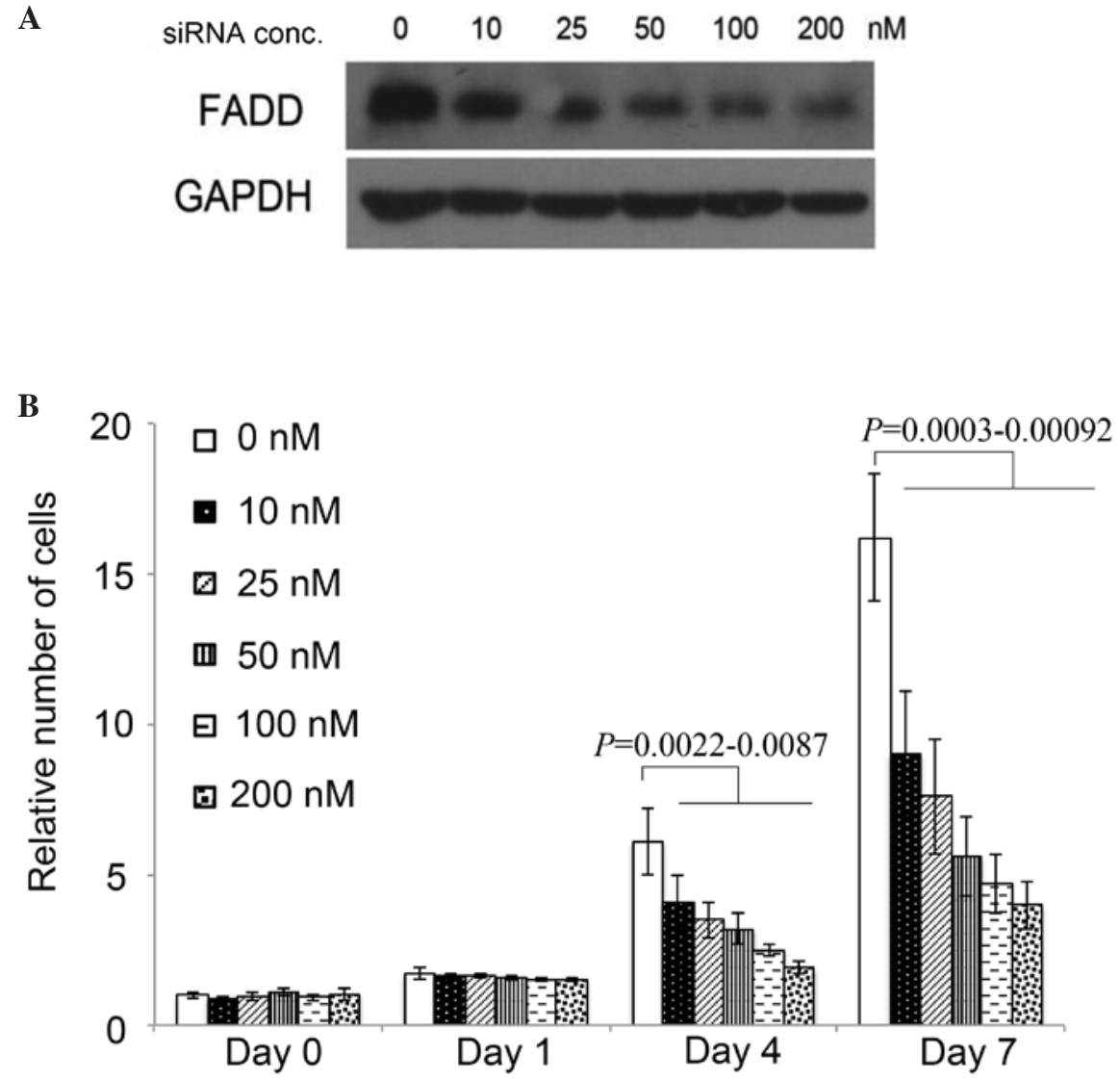

Figure 2. FADD regulates pancreatic cancer cell proliferation. Colo357 cells were transfected with FADD siRNA at the concentrations indicated. (A) The FADD protein levels corresponding to the siRNA concentrations were analyzed with western blotting. (B) Cell proliferation was determined at indicated time points $(n=6)$. Values are presented as the mean \pm standard deviation. FADD, Fas-associated death domain protein; siRNA, small interfering RNA; GAPDH, glyceraldehyde 3-phosphate aldehyde.

analysis with propidum iodide using standard flow cytometry protocols. Briefly, cells were trypsinized, fixed with cold ethanol and stored overnight at $4^{\circ} \mathrm{C}$. Cells were subsequently pelleted and rinsed in cold PBS containing RNase A and incubated for $30 \mathrm{~min}$ at $37^{\circ} \mathrm{C}$. Propidium iodide was added and incubated for an additional $30 \mathrm{~min}$ at $37^{\circ} \mathrm{C}$. Cells were analyzed using FACSCalibur ${ }^{\mathrm{TM}}$ (BD Biosciences, Franklin Lakes, NJ, USA) for the fluorescence signals collected in the FL-2 detector. A total of 100,000 events were collected. Cell cycle profiles were analyzed using FlowJo software (version 10.0.8; FlowJo, LLC, Ashland, OR, USA).

Reverse transcription-quantitative polymerase chain reaction $(R T-q P C R)$. RNA was extracted with TRIzol ${ }^{\circledR}$ reagent (Thermo Fisher Scientific, Inc.) and cDNA was synthesized with PrimeScript ${ }^{\mathrm{TM}}$ RT Master Mix (Takara Bio, Inc., Otsu, Japan) according to the manufacturer's protocol. RT-qPCR was then performed using the StepOne/StepOnePlus ${ }^{\mathrm{TM}}$ Real-time PCR system and SYBR Green PCR Master Mix (Applied Biosystems; Thermo Fisher Scientific, Inc.), according to the manufacturer's protocol. Cycling conditions were: $10 \mathrm{~min}$ of denaturation at $95^{\circ} \mathrm{C}$ and 40 cycles at $95^{\circ} \mathrm{C}$ for $15 \mathrm{sec}$ and at $60^{\circ} \mathrm{C}$ for $1 \mathrm{~min}$. The relative FADD mRNA expression level was calculated using the $2^{-\Delta \Delta \mathrm{Cq}}$ method (24), where $\Delta C_{q}$ was calculated as follows: $C_{q}$ value of FADD- $C_{q}$ value of GAPDH. PCR primers for RT-qPCR were as follows: FADD forward, ATTAATGCCTCTCCCGCA $\mathrm{CC}$ and reverse, TCTCTGCTTCGCTCCGATTC; GAPDH forward, CACCATCTTCCAGGAGCGAG and reverse, GCA GGAGGCATTGCTGAT.

Statistical analysis . Data are expressed as the mean \pm standard deviation, and paired Student's t-test analysis was performed. Comparisons within groups were conducted using a t-test with repeated measures. $\mathrm{P}<0.05$ was considered to indicate a statistically significant difference. All statistical analyses were performed with Prism software version 6.0 (GraphPad Software Inc., La Jolla, CA, USA).

\section{Results}

FADD is overexpressed in pancreatic cancer cells. To determine the expression of FADD in pancreatic cancer cells, FADD mRNA levels were examined in the wild-type epithelial cell line (HPDE6) and cancerous pancreatic cells. FADD mRNA expression was elevated significantly in pancreatic cancer cells compared to in HPDE6 cell, with P-values of $0.0051,0.0014$ and 0.0001 in MIA-PaCa-2, Colo357 and Capan-1, respectively (Fig. 1A). To confirm the changes in the FADD mRNA level, the protein levels were subsequently 

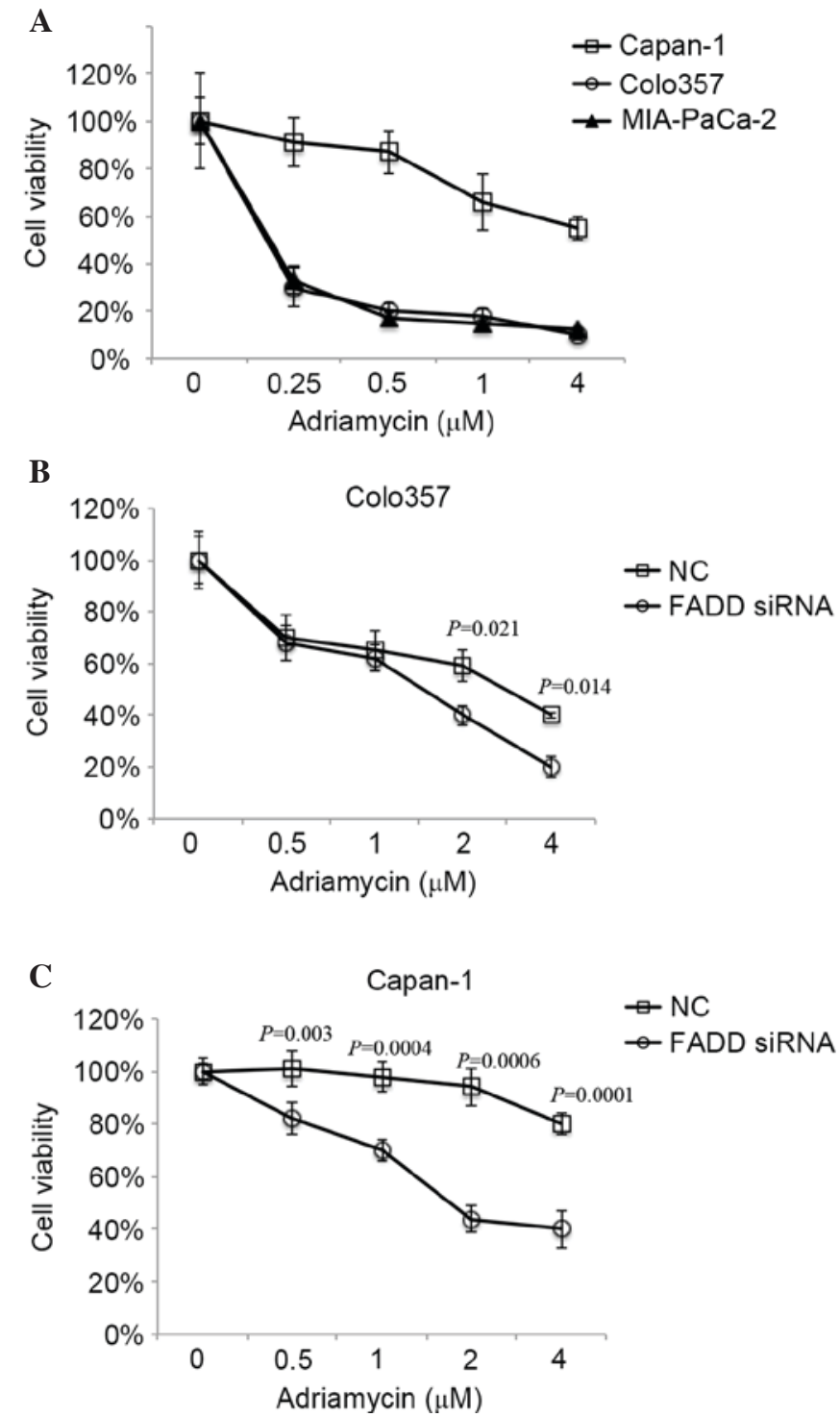

Figure 3. FADD sensitizes pancreatic cancer cells to Adriamycin. (A) Pancreatic cancer cells were treated with Adriamycin at the concentrations indicated. Cell number was determined $48 \mathrm{~h}$ following treatment $(\mathrm{n}=6)$ (B) Colo357 cells were transfected with FADD siRNA or NC for $48 \mathrm{~h}$. Cells were subsequently treated with Adriamycin at the concentrations indicated for $24 \mathrm{~h}(\mathrm{n}=6)$. (C) Capan-1 cells were transfected with FADD siRNA or NC for $48 \mathrm{~h}$. Cells were subsequently treated with Adriamycin at the concentrations indicated for $24 \mathrm{~h}(\mathrm{n}=6)$. Values are presented as the mean \pm standard deviation. FADD, Fas-associated death domain protein; siRNA, small interfering RNA; NC, negative control.

determined using western blotting. FADD protein expression was also increased in pancreatic cancer cells (Fig. 1B). Increased levels of FADD in pancreatic cancer cells were in conflict to its classic apoptotic role, suggesting a non-apoptotic functions of FADD in these cells.

FADD is required for pancreatic cancer cell proliferation. As FADD is overexpressed in pancreatic cancer cells, its effect on pancreatic cancer cell proliferation was examined. Cell proliferation was inhibited significantly by FADD RNAi at 4 days subsequent to FADD siRNA transfection compared to NC siRNA transfection, indicated by P-values of $0.0087,0.0061$, 0.0051 , and 0.0022 corresponding to the FADD siRNA concentrations of $10,25,50,100$ and $200 \mathrm{nM}$, respectively. A total

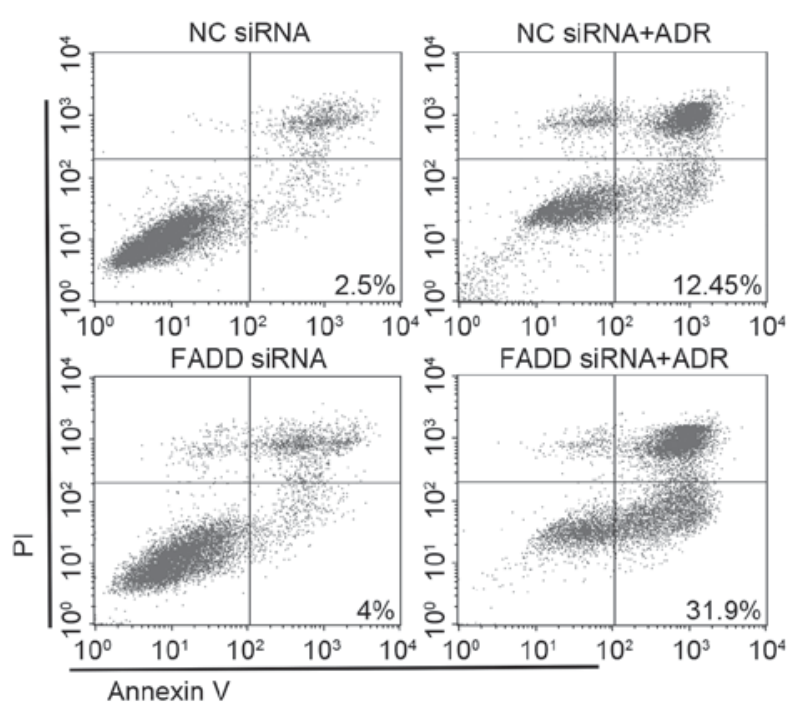

Figure 4. FADD protects pancreatic cancer cells from ADR-induced apoptosis. Capan-1 cells were transfected with NC siRNA or FADD siRNA as indicated for $48 \mathrm{~h}$. Cells were subsequently treated with ADR for $48 \mathrm{~h}$ and collected for Annexin V immunostaining. Apoptotic cells were denoted as Annexin $\mathrm{V}^{+} / \mathrm{PI}^{-}$. FADD, Fas-associated death domain protein; ADR, Adriamycin; NC, negative control; siRNA, small interfering RNA; PI, propidium iodide.

of 7 days following transfection, FADD knockdown inhibited Colo357 proliferation by $>50 \%$ with concentrations of FADD siRNA of $25 \mathrm{nM}$ or higher, , with P-values of 0.00092, 0.00045, 0.00063 and 0.0003 corresponding to FADD siRNA concentrations of 10, 25, 50, 100 and $200 \mathrm{nM}$, respectively (Fig. 2).

FADD is correlated with drug resistance in pancreatic cancer cells. It has been demonstrated that FADD is overexpressed in 3 pancreatic cancer cell lines to varying degrees (Fig. 1). It has previously been demonstrated that Capan-1 cells exhibit increased resistance to anti-cancer drugs compared with other cancer cell lines (25). As FADD is highly expressed in Capan-1, the effect of FADD on drug resistance was analyzed. The Adriamycin sensitivity of the cell lines was initially measured. Capan-1 exhibited increased resistance to Adriamycin compared with Colo357 and MIA-PaCa2 (Fig. 3A). Furthermore, FADD knockdown sensitized Colo357 to Adriamycin significantly, with P-values of 0.021 and 0.014 corresponding to Adriamycin concentrations of 2 and $4 \mu \mathrm{M}$, respectively (Fig. 3B). Additionally, FADD RNAi increased the sensitivity of Capan-1 cells to Adriamycin significantly, with P-values of $0.003,0.0004,0.0006$ and 0.0001 corresponding to Adriamycin concentrations of $0.5,1,2$ and $4 \mu \mathrm{M}$, respectively (Fig. $3 \mathrm{C}$ ). The present data indicate a promoting role for FADD in the development of drug resistance in pancreatic cancer cells.

FADD protects pancreatic cancer cells from drug-induced apoptosis. Adriamycin-induced apoptosis in FADD knockdown cells was examined. While FADD RNAi alone had no effect on apoptosis, $2 \mu \mathrm{M}$ Adriamycin treatment was able to induce a moderate level of apoptosis. FADD RNAi dramatically promoted Adriamycin-induced apoptosis (Annexin $\mathrm{V}^{+} / \mathrm{PI}$ ) (Fig. 4). The present data indicates that FADD is critical to the 
A
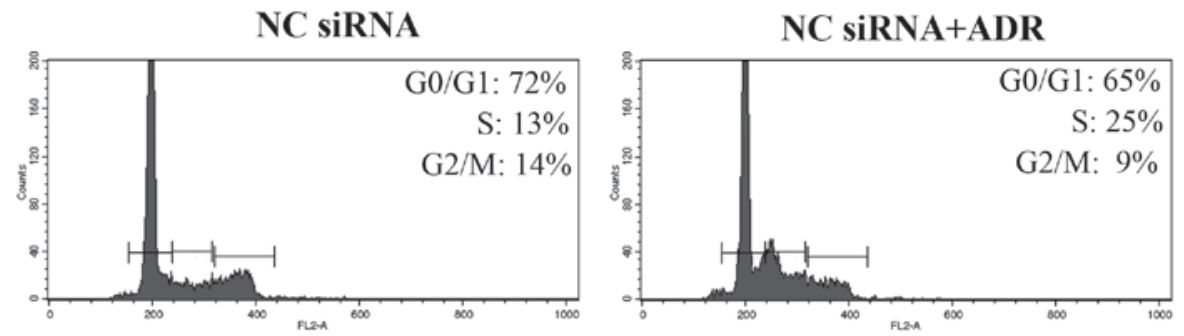

FADD siRNA

FADD siRNA+ADR
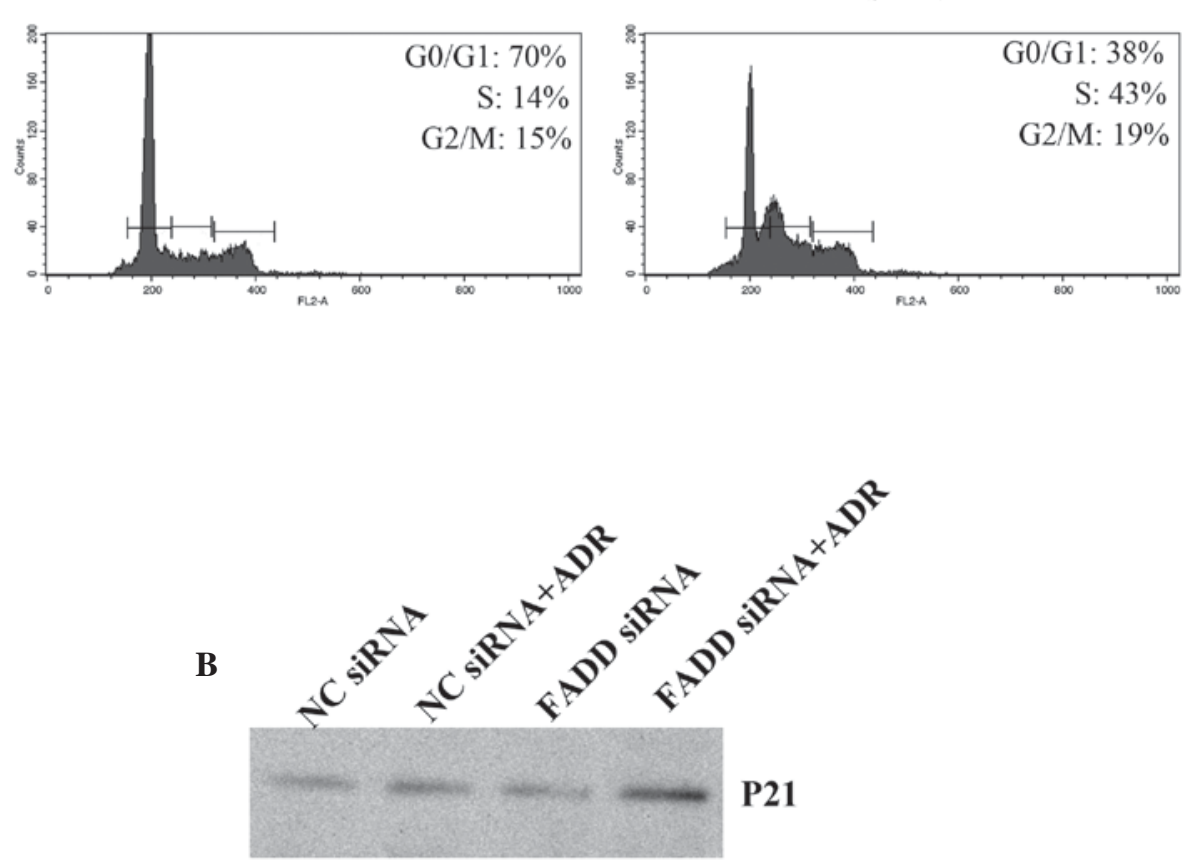

GAPDH

Figure 5. FADD regulates pancreatic cell cycle progression. (A) Capan-1 cells were transfected with NC siRNA or FADD siRNA for $48 \mathrm{~h}$. Cells were subsequently treated with ADR for $48 \mathrm{~h}$, prior to being fixed for cell cycle analysis. (B) P21 protein levels were determined in the samples from (A) by western blot analysis. FADD, Fas-associated death domain protein; NC, negative control; siRNA, small interfering RNA; ADR, Adriamycin; FL2-A, FL2-area; GAPDH, glyceraldehyde 3-phosphate dehydrogenase.

development of drug resistance in Capan-1 cells and protects them from apoptosis.

$F A D D$ regulates the cell cycle. It has been shown that Adriamycin induces cell cycle arrest, which subsequently leads to apoptosis (21). Cell cycle phase distribution in FADD knockdown Capan-1 cells was examined. Adriamycin treatment resulted in cell cycle arrest (Fig. 5A). FADD RNAi promoted increased cell cycle arrest in the $S$ phase when combined with Adriamycin treatment. p21 levels were also significantly elevated in FADD knockdown Capan-1 cells following Adriamycin treatment (Fig. 5B). Thus the present data indicate that FADD partially inhibits Adriamycin induced cell cycle arrest.

\section{Discussion}

FADD was initially identified as an adaptor protein that couples Fas receptor and procaspase- 8 to form a death-inducing signaling complex. Procaspase- 8 is subsequently cleaved leading to its activation and the initiation of apoptosis (2). It is therefore reasonable to hypothesize that FADD has a repressive role in cancer cell proliferation and survival. This concept was supported by the fact that FADD is deficient in certain types of cancer $(11,12)$. However, multiple studies have revealed that FADD is overexpressed in many other forms of cancer (14-17). Consistent with previous observations, the present study indicated that FADD is overexpressed in pancreatic cancer cells. Knockdown of FADD impairs pancreatic cancer cell proliferation, suggesting that FADD is required for cell proliferation in the context of cancer. It has been shown that FADD translocates into the nucleus during mitosis to promote cell cycle progression, implying that FADD has apoptotic and non-apoptotic roles depending upon its cellular localization $(26,27)$. Its nuclear localization promotes cell cycle progression and simultaneously deprives proliferative cells of apoptotic stimuli (18). This model proposes a 
mechanism for the FADD-mediated coupling of cancer cell proliferation and resistance to apoptosis, however further research is required (18).

In addition to facilitating proliferation, the present study also demonstrated that FADD induces drug resistance in pancreatic cancer cells, indicating that FADD is required for cancer cell survival in response to certain apoptotic stimuli. Although FADD is required for death receptor-mediated apoptosis, it is not required in Adriamycin-induced fibroblast apoptosis (5). As demonstrated by the present study, FADD deficiency results in apoptosis in response to Adriamycin in pancreatic cancer cells. This discrepancy largely depends on cellular context. Accelerated cell cycle machinery in cancer cells may be more sensitive to stimuli that cause cell cycle arrest. However, the complete mechanisms remain to be fully elucidated.

In conclusion, the present data demonstrated critical roles for FADD in pancreatic cancer cell proliferation and the development of resistance to Adriamycin. The results indicate more complex regulatory mechanisms for pancreatic cancer cell proliferation and survival. The data also reveal new strategies in the development of more efficient pancreatic cancer treatments.

\section{Acknowledgements}

The authors are grateful for grants from the National Key Basic Research Program of the Ministry of Science and Technology (grant nos. 2012CB967004, 2014CB744501 and 2011CB933502), the Chinese National Nature Sciences Foundation (grant nos. 81121062, 30425009, 30330530 and 30270291), the Jiangsu Provincial Nature Science Foundation (grant nos. BE2013630, BZ2012050 and BK2011573) and the Bureau of Science and Technology of Changzhou (grant nos. CM20122003, CZ20120004, CZ20130011 and CE20135013s).

\section{References}

1. Zhang $\mathrm{J}$ and Winoto A: A mouse Fas-associated protein with homology to the human Mort1/FADD protein is essential for Fas-induced apoptosis. Mol Cell Biol 16: 2756-2763, 1996.

2. Chinnaiyan AM, O'Rourke K, Tewari M and Dixit VM: FADD, a novel death domain-containing protein, interacts with the death domain of Fas and initiates apoptosis. Cell 81: 505-512, 1995.

3. Kuang AA, Diehl GE, Zhang J and Winoto A: FADD is required for DR4- and DR5-mediated apoptosis: Lack of trail-induced apoptosis in FADD-deficient mouse embryonic fibroblasts. J Biol Chem 275: 25065-25068, 2000.

4. Chinnaiyan AM, Tepper CG, Seldin MF, O'Rourke K, Kischkel FC, Hellbardt S, Krammer PH, Peter ME and Dixit VM: FADD/MORT1 is a common mediator of CD95 (Fas/APO-1) and tumor necrosis factor receptor-induced apoptosis. J Biol Chem 271: 4961-4965, 1996.

5. Yeh WC, de la Pompa JL, McCurrach ME, Shu HB, Elia AJ, Shahinian A, Ng M, Wakeham A, Khoo W, Mitchell K, et al: FADD: Essential for embryo development and signaling from some, but not all, inducers of apoptosis. Science 279: 1954-1958, 1998.

6. Kabra $\mathrm{NH}$, Kang $\mathrm{C}$, Hsing LC, Zhang $\mathrm{J}$ and Winoto A: $\mathrm{T}$ cell-specific FADD-deficient mice: FADD is required for early T cell development. Proc Natl Acad Sci USA 98: 6307-6312, 2001

7. Zhang J, Cado D, Chen A, Kabra NH and Winoto A: Fas-mediated apoptosis and activation-induced T-cell proliferation are defective in mice lacking FADD/Mort1. Nature 392: 296-300, 1998.

8. Zhang H, Zhou X, McQuade T, Li J, Chan FK and Zhang J: Functional complementation between FADD and RIP1 in embryos and lymphocytes. Nature 471: 373-376, 2011.
9. Osborn SL, Diehl G, Han SJ, Xue L, Kurd N, Hsieh K, Cado D, Robey EA and Winoto A: Fas-associated death domain (FADD) is a negative regulator of T-cell receptor-mediated necroptosis. Proc Natl Acad Sci USA 107: 13034-13039, 2010.

10. Welz PS, Wullaert A, Vlantis K, Kondylis V, Fernández-Majada V, Ermolaeva M, Kirsch P, Sterner-Kock A, van Loo G and Pasparakis M: FADD prevents RIP3-mediated epithelial cell necrosis and chronic intestinal inflammation. Nature 477: 330-334, 2011.

11. Newton K, Harris AW and Strasser A: FADD/MORT1 regulates the pre-TCR checkpoint and can function as a tumour suppressor. EMBO J 19: 931-941, 2000.

12. Tourneur L, Delluc S, Lévy V, Valensi F, Radford-Weiss I, Legrand O, Vargaftig J, Boix C, Macintyre EA, Varet B, et al: Absence or low expression of fas-associated protein with death domain in acute myeloid leukemia cells predicts resistance to chemotherapy and poor outcome. Cancer Res 64: 8101-8108, 2004.

13. Fantl V, Smith R, Brookes S, Dickson C and Peters G: Chromosome 11q13 abnormalities in human breast cancer. Cancer Surv 18: 77-94, 1993.

14. Gibcus JH, Menkema L, Mastik MF, Hermsen MA, de Bock GH, van Velthuysen ML, Takes RP, Kok K, Alvarez Marcos CA, van der Laan BF et al: Amplicon mapping and expression profiling identify the Fas-associated death domain gene as a new driver in the 11q13.3 amplicon in laryngeal/pharyngeal cancer. Clin Cancer Res 13: 6257-6266, 2007.

15. Prapinjumrune C, Morita K, Kuribayashi Y, Hanabata Y, Shi Q, Nakajima $Y$, Inazawa $\mathbf{J}$ and Omura K: DNA amplification and expression of FADD in oral squamous cell carcinoma. J Oral Pathol Med 39: 525-532, 2010.

16. Rasamny JJ, Allak A, Krook KA, Jo VY, Policarpio-Nicolas ML, Sumner HM, Moskaluk CA, Frierson HF Jr and Jameson MJ: Cyclin D1 and FADD as biomarkers in head and neck squamous cell carcinoma. Otolaryngol Head Neck Surg 146: 923-931, 2012.

17. Kwek SS, Roy R, Zhou H, Climent J, Martinez-Climent JA, Fridlyand $\mathrm{J}$ and Albertson DG: Co-amplified genes at $8 \mathrm{p} 12$ and $11 \mathrm{q} 13$ in breast tumors cooperate with two major pathways in oncogenesis. Oncogene 28: 1892-1903, 2009.

18. Chen G, Bhojani MS, Heaford AC, Chang DC, Laxman B, Thomas DG, Griffin LB, Yu J, Coppola JM, Giordano TJ, et al: Phosphorylated FADD induces NF-kappaB, perturbs cell cycle, and is associated with poor outcome in lung adenocarcinomas. Proc Natl Acad Sci USA 102: 12507-12512, 2005.

19. Siegel R, Naishadham D and Jemal A: Cancer statistics, 2012. CA Cancer J Clin 62: 10-29, 2012.

20. Andrán-Sandberg A: Pancreatic cancer: Chemotherapy and radiotherapy. N Am J Med Sci 3: 1-12, 2011.

21. King KL and Cidlowski JA: Cell cycle regulation and apoptosis. Annu Rev Physiol 60: 601-617, 1998.

22. Varfolomeev E, Maecker H, Sharp D, Lawrence D, Renz M, Vucic D and Ashkenazi A: Molecular determinants of kinase pathway activation by Apo2 ligand/tumor necrosis factor-related apoptosis-inducing ligand. J Biol Chem 280: 40599-40608, 2005.

23. Cheng W, Wang L, Zhang R, Du P, Yang B, Zhuang H, Tang B, Yao C, Yu M, Wang Y, et al: Regulation of protein kinase C inactivation by Fas-associated protein with death domain. J Biol Chem 287: 26126-26135, 2012.

24. Schmittgen TD and Livak KJ: Analyzing real-time PCR data by the comparative C(T) method. Nat Protoc 3: 1101-1108, 2008.

25. Arlt A, Vorndamm J, Breitenbroich M, Fölsch UR, Kalthoff H, Schmidt WE and Schäfer H: Inhibition of NF-kappaB sensitizes human pancreatic carcinoma cells to apoptosis induced by etoposide (VP16) or doxorubicin. Oncogene 20: 859-868, 2001.

26. Alappat EC, Feig C, Boyerinas B, Volkland J, Samuels M, Murmann AE, Thorburn A, Kidd VJ, Slaughter CA, Osborn SL, et al: Phosphorylation of FADD at serine 194 by CKIalpha regulates its nonapoptotic activities. Mol Cell 19: 321-332, 2005 .

27. Cheng W, Wang L, Yang B, Zhang R, Yao C, He L, Liu Z, Du P, Hammache K, Wen J, et al: Self-renewal and differentiation of muscle satellite cells are regulated by the Fas-associated death domain. J Biol Chem 289: 5040-5050, 2014. 